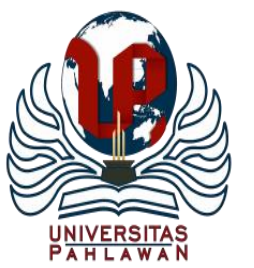

Jurnal Basicedu Volume 4 Nomor 3 Tahun 2020 Halm. 586- 592

JURNAL BASICEDU

Research \& Learning in Elementary Education

https://jbasic.org/index.php/basicedu/index

\title{
Pengaruh Model Kooperatif Tipe Jigsaw Terhadap Hasil Belajar Pada Pembelajaran IPS Siswa Sekolah Dasar
}

\author{
Faddylla Intan Maharani ${ }^{1}$, Taufina ${ }^{2}$ \\ Universitas Negeri Padang, Sumatera Barat, Indonesia ${ }^{1,2}$ \\ E-mail : faddyllaintanmaharani@yahoo.com ${ }^{1}$, taufina@ fip.unp.ac.id ${ }^{2}$
}

\begin{abstract}
Abstrak
Penelitian ini dilakukan untuk mengetahui apakah model Kooperatif Tipe Jigsaw berpengaruh terhadap hasil belajar IPS siswa kelas IV SD Negeri 07 KTK Kota Solok. Jenis penelitian ini yaitu quasi experimen, datadata dikumpulkan melalui tes dan observasi. Kemudian dilakukan uji normalitas, homogenitas, dan hipotesis. Sampel penelitian diambil dari seluruh anggota populasi yang berjumlah 42 orang, kelas IV A sebanyak 21 orang sebagai kelas eksperimen dan kelas IV B sebanyak 21 orang sebagai kelas kontrol. Hipotesis penelitian dianalisis menggunakan uji-t dengan hasil $t_{\text {hitung }} 2,498$ dan $t_{\text {tabel }} 2,093$, maka 0,015 2,093 dengan taraf signifikansi $95 \%$. Keputusannya yaitu Ha diterima. Maka terdapat pengaruh penggunaan model Kooperatif Tipe Jigsaw terhadap hasil belajar IPS siswa kelas IV di SD Negeri 07 KTK Kota Solok.

Kata Kunci: hasil belajar, IPS, kooperatif tipe jigsaw
\end{abstract}

\begin{abstract}
The present study purposes to examine the effect of Jigsaw on the learning outcomes of Social Studies students of grade IV SD Negeri 07 KTK Kota Solok. This is a quasi-experiment with tests and observation as its instruments. The normality, homogeneity, and hypothesis testing were conducted throughout the study. The total sampling was used in this research, 21 students in class A were selected as experimental class, and 21 students in class $B$ were selected as control class. The hypothesis analysis were conducted through $t$-test with tcount 2.498 and ttable 2.093, then $0.015<2.093$ with a significance level of 95\%. Ha is accepted then showed that the use of Jigsaw on the social studies can affects the students' learning outcome.
\end{abstract}

Keywords: Learning outcomes, Social Studies, Cooperative of jigsaw type

Copyright (c) 2020 Faddylla Intan Maharani, Taufina

$\square$ Corresponding author :

Address : Komp.Pandan Puti Indah, Kota Solok, SUMBAR

ISSN 2580-3735 (Media Cetak)

Email : faddyllaintanmaharani@yahoo.com

ISSN 2580-1147 (Media Online)

Phone : 082171107141

DOI: https://doi.org/10.31004/basicedu.v4i3.402 


\section{PENDAHULUAN}

Sekarang ini kemajuan teknologi telah menjadi fokus dalam pendidikan dasar, anak-anak usia sekolah dasar sudah mahir dalam menggunakan teknologi digital untuk memenuhi kebutuhan mereka dalam kehidupan sehari-hari (Taufina et al., 2019). Kualitas pendidikan sangat berpengaruh pada kemajuan dan perkembangan suatu negara agar terciptanya generasi penerus yang baik (Moh Rifai, Nyoto Hardjono, 2019). Tujuan utama dalam pendidikan tidak hanya mengatur pengetahuan, kemampuan, keterampilan melainkan dalam lingkungan keseharian (Yulianti \& Fauzan, 2019). Dalam hal ini guru berinisiatif untuk mengembangkan kreatifitasnya sesuai dengan konten yang disukai siswa dalam belajar (Heafner, 2018). Mengungkapkan isu sosial yang sedang terjadi dapat merangsang siswa agar berpikir untuk menyelesaikan masalah jika terjadi pada lingkungannya (Howell \& Saye, 2018).

Sebagai pendidik guru merupakan motivator sekaligus pendamping bagi siswa saat belajar dalam kelas, guru jugalah yang membuat kondisi ruang kelas menjadi nyaman dan kondusif serta menyenangkan agar siswa tertarik untuk mengikuti pembelajaran khususnya dalam pelaksanaan ilmu pengetahuan sosial (Daryanti, 2020). Untuk mendukung pelaksanaan pembelajaran di sekolah maka guru harus berdedikasi tinggi, berwawasan yang luas dan berkualitas agar para siswa terdorong untuk berprestasi dalam belajar. Tidak hanya mampu mengembangkan ilmu guru juga harus bisa merancang strategi dan cara agar potensi siswa dapat dikembangkan dan siswa merasa percaya diri (Nelli Herawani,Yanti Fitria, 2018).

Tujuan tersebut dapat tercapai jika dalam proses pembelajaran IPS, guru dapat memberikan kebebasan dalam beraktivitas dan bertindak sebagai fasilitator, motivator serta mampu dalam melahirkan pembelajaran sesuai dengan zaman yang berkembang saat ini (Maharani \& Montessori, 2020). Perkembangan zaman yang begitu cepat mempengaruhi seorang pendidik dalam memakai berbagai strategi mengajar yang efektif untuk mengembangkan pengetahuan dan juga kepribadian siswa menjadi masyarakat peduli akan lingkungan sekitarnya (Tri Juna Irawana, 2020).

Selama ini dalam pembelajaran IPS terdapat sajian menarik berbentuk fakta, pemahaman kering, dan pendidik yang cuma mengerjar tingkat capaian kurikulum serta proses pembelajaran dianggap kurang penting menjadi persoalan, akibatnya jenuh dan membosankan sering terjadi saat proses belajar IPS bagi siswa. Tidak hanya itu siswa menganggap bahwa pembelajaran IPS dapat dikesampingkan dari pada pembelajaran yang lain (Delviati, 2015).

Dalam pembelajaran seorang pendidik seharusnya dapat menerapkan model yang cocok dalam proses belajar untuk memancing partisipasi belajar siswa, karena model yang digunakan guru akan berdampak terhadap proses pembelajarannya (Efendi et al., 2019). Dalam pembelajaran kooperatif, keterlibatan aktif dan langsung siswa dalam proses pembelajaran mengarah pada pengembangan yang komprehensif. Belajar mandiri dan motivasi pada pembelajaran berfokus 
pada peran siswa dalam proses belajar (Sanaie et al., 2019).

Terjadi interaksi timbal balik antar siswa saat bekerja sama pada tim agar materi dikuasai dengan baik dan maksimal dalam belajar adalah cara tertentu model Kooperatif Tipe Jigsaw untuk mencapai hasil yang baik (Isjoni, 2011:54). Melalui model Kooperatif Tipe Jigsaw dituntut agar bisa memahami materi yang tidak hanya di peruntukkan pada kelompoknya saja, melainkan nanti juga akan dituntut untuk berdiskusi dengan anggota kelas yang termasuk dalam kelompok ahli, ketika materinya sudah dipahami dan dimengerti siswa untuk dijelaskan kepada teman-teman anggota kelompok asalnya (Gusmayeni, Fachri Adnan, 2019).

Dalam peranannya Kooperatif Tipe Jigsaw ini diharapkan siswa mampu mengembangkan cara berfikir yang tinggi supaya saat berinteraksi dalam timnya timbul rasa kompak dan serius terhadap pelajaran dapat membuatnya terpacu dalam belajar. Menemukan konsep dan memahami pembelajaran yang guru sajikan dikelas pada pelajaran IPS dapat dipahami siswa saat menerapkan model Kooperatif Tipe Jigsaw. Seorang pendidik perannya tidak lagi narasumber namun menjadi pendamping dalam proses pembelajaran (Rusdinal Marta, 2017).

Informasi yang diperoleh saat observasi dan wawancara bersama guru kelas IV SD Negeri 07 KTK Kota Solok, hasil yang di dapatkan diantaranya siswa kelas IV dengan pembelajaran IPS terlihat sangat menonjol rendahnya diantara nilai-nilai mata pelajaran lain dan memiliki hasil dibawah KKM masih terlihat banyak. Sebagian siswa kurang mengetahui dan belum mampu mengerti serta tidak memahami pelajaran IPS.

Rendahnya nilai pelajaran IPS siswa disebabkan masih banyak siswa yang belum mampu mengerti dan memahami pembelajaran IPS, dan juga proses pembelajaran yang masih mengutamakan hapalan dari pada penerapan, serta pembelajaran terpusat pada guru (teacher center) bukan terpusat pada siswa (student center) seperti terlihat saat observasi ditetapkan penggunaan model konvensional dengan menggunakan metode ceramah saat menerangkan pelajaran. Kebiasaan guru dalam menggunakan metode tanya jawab dan ceramah sudah menjadi kebiasaan dalam mengajar, guru merasa tidak puas jika tidak berceramah saat dikelas. Efeknya berdampak kepada siswa yang belajar jika gurunya berceramah didepan kelas karena keterbiasaan dalam mendengarkan pelajaran saja (Sanjaya Wina, 2006).

Jika hanya mengandalkan model konvensional seperti ceramah dalam pembelajaran, maka sebagian siswa pasti tidak akan terlalu serius dalam memahami pembelajaran tersebut. Pembelajaran IPS akan dianggap tidak penting lalu akan dikesampingkan diantara pelajaran lainnya. Siswa juga beranggapan bahwa IPS hanyalah persoalan menghapal, karena itu guru harus menerapkan model dalam pelajaran IPS supaya pembelajaran lebih menyenangkan dan dapat diterapkannya pada kehidupan masing-masing.

Berdasarkan masalah di atas melatar belakangi peneliti untuk memberikan sebuah solusi berupa model pembelajaran Kooperatif Tipe Jigsaw dianggap cocok digunakan dalam proses 
belajar mengajar di sekolah dasar pada pembelajaran IPS, sehingga penggunaan model dalam kegiatan belajar dapat meningkatkan kemampuan peserta didik untuk memecahkan suatu masalah dan juga membantu siswa dalam menguasai konsep yang dipelajari sehingga terjadi peningkatan hasil belajarnya.

\section{METODE}

Pendekatan dan pengumpulan data dilakukan secara kuantitatif, data berupa angkaangka kemudian dianalisis menggunakan statistik. Penelitian kuantitatif dilakukan ketika menginginkan data yang pasti dan jika ingin mengetahui pengaruh atau pengolahan pasti terhadap permasalahan yang diamati (Sugiyono, 2013).

Penelitian ini menggunakan metode yaitu eksperimen dengan jenis quasy experiment atau eksperimen semu. Menurut Arikunto (2013) dikatakan seperti itu sebab eksperimen jenis ini belum memenuhi syarat seperti eksperimen yang mengikuti aturan ilmiah. Sementara metode eksperimen bersifat validation atau menguji, yaitu menguji pengaruh satu atau lebih variabel terhadap variabel lain yang ada pada penelitian (Nana, 2010).

Penggunaan variabel independent pada penelitian ini menggunakan model Kooperatif Tipe Jigsaw dalam pembelajaran IPS dan hasil belajar sebagai variabel dependen pada penelitian. Penggunaan teknik purposive sampling dalam pengambilan sampel dan juga terdapat dua kelas sebagai sampel yaitu kelas eksperimen dan kelas kontrol. Penelitian ini berlokasi di SD Negeri 07
KTK Kota Solok dengan melibatkan seluruh siswa kelas IV sebanyak 42 orang yang masing-masing berjumlah 21 orang siswa kelas IVA ditetapkan sebagai kelas eksperimen dan 21 orang siswa IVB ditetapkan sebagai kelas kontrol akan menjadi sampel saat penelitian.

Teknik dalam mengumpulkan data penelitian dari hasil tes kemampuan awal sebagai acuan untuk mengetahui pemahaman siswa terkait pokok bahasan yang diujikan. Data di analisis menggunakan uji-t, yang sebelumnya melakukan pengujian normalitas dan homogenitas. Untuk penyajian data yang telah di dapatkan melalui hasil pre-test dan hasil akhir post-test pada semua proses kegiatan pembelajaran di kedua kelas sampel.

\section{HASIL DAN PEMBAHASAN}

Pembelajaran yang telah dilaksanakan oleh peneliti di SD Negeri 07 KTK Kota Solok selama empat kali pertemuan, secara keseluruhan pelaksanaan kegiatan pembelajaran di kedua kelas sampel dengan soal berjumlah 24 butir soal masuk pada kriteria terlaksana dengan baik sesuai dengan RPP dan aman meskipun ada beberapa perbedaan respon yang ditunjukkan siswa pada kedua sampel selama proses pembelajaran dilakukan.

Respon siswa kelas eksperimen menunjukkan respon yang baik saat pembelajaran berlangsung. Namun ada tahap kegiatan di pembelajaran memperoleh skor terendah yaitu pada tahap ulangi dipertemuan ketiga dimana setengah dari jumlah seluruh siswa bertanya pada materi yang belum dipahami saat setelah dilakukan latihan. Meski demikian siswa yang bertanya hanyalah sebagian anggota kelas saja yang 
materinya belum mampu dipahami. Secara keseluruhan, anggota kelas eksperimen menunjukkan emosi positif selama kegiatan pembelajaran dari awal hingga akhir.

Emosi positif tersebut ditandai dengan rasa ingin tahu yang tinggi, siswa terlihat senang dan terbawa suasana dalam mengikutu kegiatan pembelajaran, sehingga lupa dengan waktu. Banyak siswa yang aktif saat diskusi kelompok, diantara masing-masing kelompok berlombalomba dalam menjawab pertanyaan saat diskusi tersebut. Sikap tersebut menunjukkan sebagian penerapan pada model Kooperatif Tipe Jigsaw dalam proses pembelajaran sehingga akan berpengaruh juga terhadap otak siswa saat mengingat pelajaran, sehingga dapat menumbuhkan keberhasilan dalam belajar pada siswa.

Sementara itu langkah pembelajaran pada kelas kontrol yang dianggap kurang mendapatkan respon dari siswa adalah saat kegiatan pembelajaran berlangsung. Hanya beberapa siswa saja yang berani bertanya dan mengeluarkan inisiatif untuk berbicara dalam menjawab pertanyaan meskipunmateri yang diberikan belum di kuasai seluruhnya. Hal ini terlihat saat perilaku siswa yang tampak tidak terlalu aktif dan antusias selama proses pembelajaran berlangsung. Siswa merasa tidak percaya diri dan terlihat malu-malu saat ditanya maupun menjawab pertanyaan. Hal inilah menjadi pemicu menurunnya keaktifan saat belajar siswa dikelas yang mempengaruhi hasil pembelajarannya. Hasil pembelajaran tersebut disajikan dalam tabel berikut:
Tabel 1. Perbedaan Capaian Hasil Belajar Kelompok Eksperimen dan Kelompok Kontrol

\begin{tabular}{|c|c|c|}
\hline Kelas & Nilai Rata-rata & Persentase \\
\hline Eksperimen & 81,54 & $52,16 \%$ \\
\hline Kontrol & 74,79 & $47,84 \%$ \\
\hline
\end{tabular}

Tabel di atas menunjukkan perbedaan capaian hasil belajar kedua kelas sampel. Nilai rata-rata kelas eksperimen yaitu 81, 54, dimana persentasenya 52, 16\% dan kelas kontrol hanya mencapai rata-rata sebesar 74,79 yang mana persentasenya $47,84 \%$. Ini adalah perbedaan yang didapatkan setelah kedua kelas diberikan pemahaman materi tentang perkembangan teknologi tetapi dengan model pembelajaran yang berbeda. Dimana saat penggunaan model Kooperatif Tipe Jigsaw dikelas jumlah hasil didapat 81, 54 dan ketika tidak menggunakan model hanya 74, 79. Capaian belajar pada pembelajaran IPS kedua kelas sampel sangat berbeda karena kelas eksperimen lebih mengungguli 6, 75 angka dari pada kelas kontrol. Keunggulan hanya didapatkan pada kelas eksperimen membuktikan bahwa kesesuaian topik materi dengan model pembelajaran Kooperatif Tipe Jigsaw yang digunakan mempengaruhi hasil belajarnya.

Selanjutnya, proses pembelajaran IPS dengan materi Perkembangan Teknologi melakukan uji normalitas yang menggunakan uji Liliefors yang menunjukkan hasil pada tabel berikut: 
Tabel 2. Uji Normalitas

Tests of Normality

\begin{tabular}{|l|r|r|r|r|r|r|}
\hline \multirow{2}{*}{} & \multicolumn{3}{|c|}{$\begin{array}{c}\text { Kolmogorov- } \\
\text { Smirnov }\end{array}$} & \multicolumn{3}{|c|}{ Shapiro-Wilk } \\
\cline { 2 - 7 } & Statistic & Df & Sig. & Statistic & \multicolumn{1}{c|}{ df } & Sig. \\
\hline Post (E) & .176 & 21 & .090 & .855 & 21 & .005 \\
Post & .180 & 21 & .075 & .949 & 21 & .325 \\
\hline K) & & & & & & \\
\hline
\end{tabular}

Lilliefors Significance

Correction

Diperoleh nilai normalitas data yang lebih besar dari 0,05 sehingga disimpulkan bahwa data penelitian berdistribusi normal. Untuk mengetahui homogenitas data, yang prosesnya menggunakan SPSS. Hasil perhitungan uji homogenitas ini dapat dibaca pada tabel berikut:

Tabel 3. Uji Homogenitas

Test of Homogeneity of Variances

Posttest

\begin{tabular}{|c|c|c|c|}
\hline Levene Statistic & df1 & $\mathrm{df} 2$ & Sig. \\
\hline .932 & 4 & 13 & .475 \\
\hline
\end{tabular}

Dengan demikian disimpulkanlah bahwa data nilai posttest bersifat homogen. Setelah itu langkah berikutnya pengujian hipotesis, kedua hasil uji diatas selanjutnya dijadikan dasar dalam uji-t untuk mengambil keputusan, berdasarkan hasil hipotesis yang dirumuskan. Hasil pengujian menunjukkan nilai $t_{\text {hitung }}=2,498$ dan nilai $t_{\text {tabel }}$ $=2,093$, maka $0,015<2,093$. Nilai signifikasi yang diperoleh $=0,015$ dan ternyata $<0,05$. Mengacu pada ketentuan pengambilan keputusan uji hipotesis maka Ha diterima. Kesimpulannya terdapat pengaruh penggunaan model pembelajaran Kooperatif Tipe Jigsaw terhadap hasil belajar IPS siswa kelas IV di SD Negeri 07 KTK Kota Solok dibandingkan dengan kelas yang tidak menerapkan model Kooperatif Tipe Jigsaw.

\section{SIMPULAN}

Dari hasil penelitian dapat diuraikan dan ditarik kesimpulan bahwa model Kooperatif Tipe Jigsaw berpengaruh terhadap hasil belajar kelas IV pada pembelajaran IPS di kelas eksperimen dan memperlihatkan respon dengan baik saat kegiatan belajar. Terbukti saat antusiasnya anggota kelas eksperimen saat bekerjasama dalam tim nya saat mendiskusikan materi yang di dapatkan dari kelompok ahli. Perbedaan juga terlihat pada hasil belajar kedua sampel dimana kelas eksperimen lebih unggul dengan rata-rata 81,54 dari pada kelas kontrol yang hanya 74,79 . Terbukti bahwa dengan menggunakan model belajar ini maka telah berhasilnya siswa dikelas IV SD Negeri 07 KTK Kota Solok.

\section{DAFTAR PUSTAKA}

Arikunto. (2013). Prosedur Penelitian. Rineka Cipta.

Daryanti, T. (2020). PENGGUNAAN MEDIA PEMBELAJARAN DALAM MODEL PICTURE AND PICTURE. Jurnal Basicedu, 4(2), 484-490.

Delviati, E. (2015). STUD1 IMPLEMENTASI KURIKULUM 2013 PADA MATA PELAJARAN IPS DI SMP SBSNP KABUPATEN AGAM SUMBAR. Jurnal Wawasan Pendidikan Dan Pembelajaran, 6(1).

Efendi, N., Fitria, Y., Padang, U. N., Padang, U. N., Padang, U. N., Education, C. G., \& Padang, U. N. (2019). Improved Student Participation of Mind To Learning Thematic 
Using Community Technology Science ( Stm ) Science Approach Class Iv in Primary. 1(2), $178-187$.

Gusmayeni, Fachri Adnan, M. (2019). PENGARUH MODEL PEMBELAJARAN KOOPERATIF TIPE JIGSAW DAN MOTIVASI BELAJAR TERHADAP HASIL BELAJAR IPS SISWA KELAS V SD. Jurnal Basicedu, 2(23), 508-513.

Heafner, T. L. (2018). More social studies?: Examining instructional policies of time and testing in elementary school. Journal of Social Studies Research, 42(3), 229-237. https://doi.org/10.1016/j.jssr.2017.08.004

Howell, J. B., \& Saye, J. W. (2018). Integrating theory and practice: Factors shaping elementary teachers' interpretation of an inquiry model for teaching social studies. Journal of Social Studies Research, 42(2), 201-214.

https://doi.org/10.1016/j.jssr.2017.04.003

Isjoni. (2011). Cooperativ Learning, Mengembangkan Kemampuan Belajar Berkelompok. Alfabeta.

Maharani, F. I., \& Montessori, M. (2020). PENINGKATAN KEMAMPUAN PEMECAHAN MASALAH SISWA SEKOLAH DASAR MENGGUNAKAN MODEL PROBLEM-BASED LEARNING. Primary: Jurnal Pendidikan Guru Sekolah Dasar, 9(April), 228-234.

Moh Rifai, Nyoto Hardjono. (2019). METAANALISIS KEEFEKTIFAN MODEL PEMBELAJARAN STUDENT TEAM ACHIEVEMENT DIVISION (STAD) DALAM MENINGKATKAN HASIL BELAJAR IPS SISWA SD. Primary: Jurnal Pendidikan Guru Sekolah Dasar, 8(October), 161-173.

Nana. (2010). Metode Penelitian Pendidikan. PT Remaja Rosdakarya.

Nelli Herawani,Yanti Fitria, H. (2018). PENINGKATAN HASIL BELAJAR MENGENAL JENIS-JENIS PEKERJAAN MELALUI METODE JIGSAW DENGAN MEDIA POP UP DI KELAS III SDN 11
AIR KALAM. Jurnal Basicedu, 3(2), 372 377.

Rusdinal Marta. (2017). Peningkatan Hasil Belajar Luas Bangun Datar Melalui Model Kooperatif Tipe Jigsaw Bagi Siswa Kelas V SD Negeri 003 Bangkinang Kota. Jurnal Basicedu, 1(1), 45-54.

Sanaie, N., Vasli, P., Sedighi, L., \& Sadeghi, B. (2019). Comparing the effect of lecture and Jigsaw teaching strategies on the nursing students' self-regulated learning and academic motivation: A quasi-experimental study. Nurse Education Today, 79(May), 3540.

https://doi.org/10.1016/j.nedt.2019.05.022

Sanjaya Wina. (2006). Strategi Pembelajaran Berorientasi Standar Proses Pendidikan. Kencana Prenada Media Group.

Sugiyono. (2013). Metode Penelitian Kuantitatif, Kualitatif dan $R \& D$. Alfabeta.

Taufina, Chandra, \& Kharisma, A. (2019). Technology integration in thematic learning to welcome the era of the industrial revolution 4.0 in elementary schools. Proceeding Internasional Seminar of Primary Education, 2, 10-19. https://doi.org/https://doi.org/10.24114/esjpg sd.v9i1.14297

Tri Juna Irawana, T. (2020). Penggunaan Metode Problem Solving untuk Meningkatkan Motivasi dan Hasil Penilaian Pendidikan Kewarganegaraan Peserta Didik di Sekolah Dasar. Jurnal Basicedu, 4(2), 434-442.

Yulianti, D., \& Fauzan, A. (2019). Development of Local Instruction Theory Topics Lowest Common Multiple and Greatest Common Factor Based on Realistic Mathematics Education in Primary Schools. International Journal of Educational Dynamics, 1(1), 222235. https://doi.org/10.24036/ijeds.v1i1.59 